\title{
CONVERGENT ASPECTS IN ENGINEERING AND ENVIRONMENTAL GEOPHYSICS, ILLUSTRATED BY CASE HISTORIES
}

\author{
G.-P. MERKLER, D. HANNICH \\ Karlsruhe University, Dept. of Applied Geology, \\ Kaiserstr. 12, D-76128 Karlsruhe, Germany
}

The goals, possible solutions and characteristic difficulties, that define convergent aspects in engineering and environmental geophysics will be discussed. The two independent branches of applied geophysics, i.e., engineering and environmental geophysics, should both be considered as aids of the geosiences, of the structural engineering and of the environmental research. The key for a succesful application of engineering or environmental geophysical measurements is the conversion of the obtained results into terms of structural engineering, geotechnical and hydrogeological language.

The adaption of classical geophysical methods to engineering geophysics was not easy. The geophysicists in the early years of engineering geophysics had to adjust the methods to new dimensions, shallower penetration depths (in the range of meters), high measurement resolution, high precision and a poor ratio signal/noise, which also brought about new developments in the technical eqipment, however.

From the authors point of view, engineering geophysics as a subfield of geosciences, can be applied only in association with engineering geology, classical geology, structural geology, civil engineering, geotechnics, geomechanics, soil and rock mechanics.

Some case studies were presented to illustrate the application of typical methods of engineering geophysics, for detection of leaks in a sheet-pile wall, in dams and for the investigation of sealing walls. An example of environmental geophysics is presented in detection and monitoring of contaminat exfiltration from a toxic industrial waste site deposit.

The first example deals with the use of thermometric measurement in finding infiltration zones in the sheet-pile wall of a foundation pit. Because the sheet-pile slats were not rammed deep enough into a clay layer, the infiltrations could not be brought under $240 \mathrm{~m}^{3} /$ hour. The results of the thermometric investigations and the depth-related spreading of warm-water infiltrations in the foundation pit are illustrated in figure 1 , which pointed to leaks in the sewer system at the west side of the foundation pit. The results of these measurements led to the reramming of the slats in the area identified by geophysical measurements as defective, and the construction could be continued and successfully completed.

The second example of engineering geophysical application deal with the detection of leakages in a long side dam of a water way by tempearture (classic and infrared) measurements in the drainage ditch and by geoelectric measurements (mise-à-la-masse method) on the dam.

The results of the temperature measurements in piezometers and by special temperature sounding drills are presented in figure 2 . Anomalies of higher temperature $\left(23^{\circ} \mathrm{C}\right)$ appears in sections of the dam and of the berme, indicating zones of water infiltration from the river to the drainage ditch. Geoelectric (mise-à-la-masse) measurements along the dam completed and confirm this supposition. 


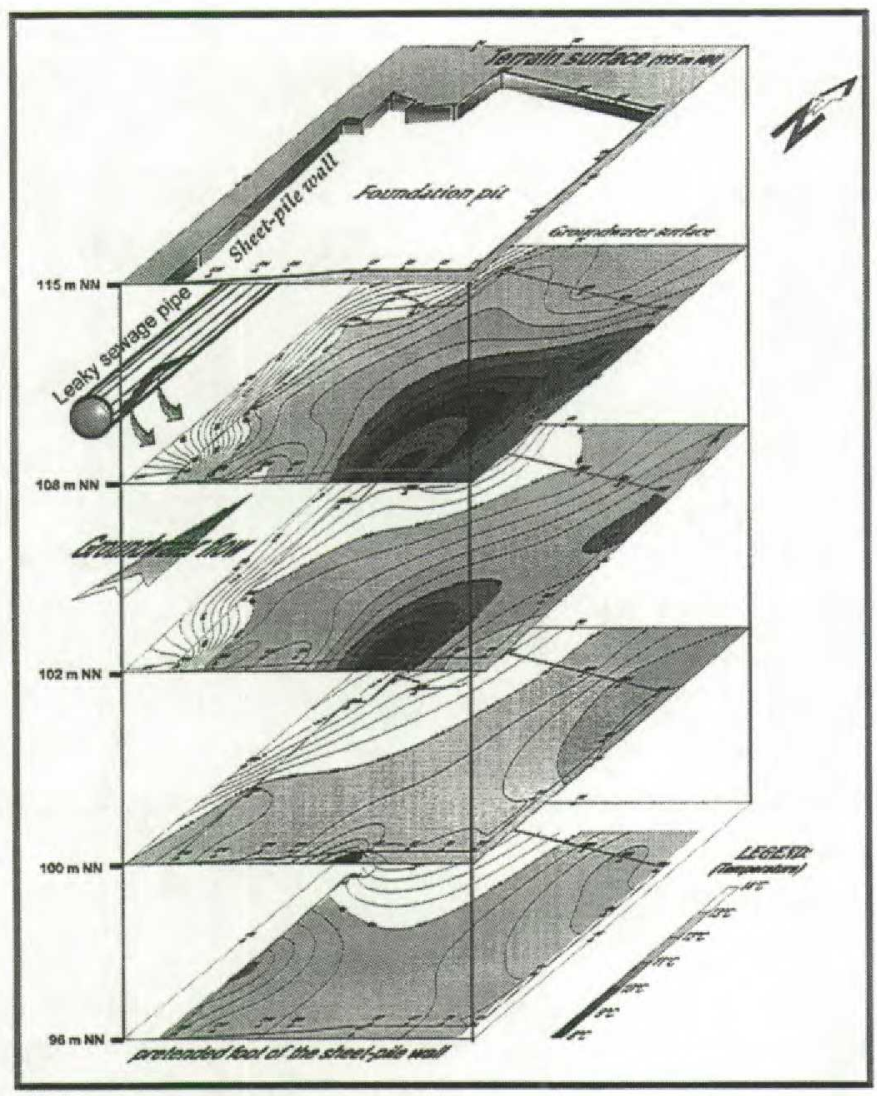

Figure 1: Depth related temperature distribution inside and outside of a foundation pit

The search for leaks or areas of seepage in sealing walls, which serve mainly as protection against the exfiltration of contaminants or protection from infiltration, can be considered as one of the most important tasks of environmental geophysics. In contrast to engineering geophysics, whose goals are the observation, description and characterization of the geological aspects of basement, environmental geophysics concentrates selectively on the survey and characterization of the physico-chemical processes -- mainly of the anthropogenic type -- into the soil and subsurface. Therefore, the demands made on environmental geophysics are just as complicated and sometimes more difficult to solve than those made of engineering geophysics.

In an example of environmental geophysical investigations on the area of a high toxic waste site deposite, were applied methods of induced polarization to study the development in time and space of the exfiltrating contamination. Also, by repeated mise-à-la-masse measurements at electrodes in a builded sealing wall, the impermeability of this sealing wall is monitored.

In figure 3 , the depth distribution of the polarization anomalies on the west side of the waste site deposite can be seen. The environmental geophysical data obtained from the induced polarisation measurements complement the hydrogeological and hydrochemical data related to the extent of the contamination.

In the last example, chosen to illustrate specifically the convergence of engineering and environmental geophysics, is presented how, with the help of mise-á-la-masse measurements, were detected inhomegenities in a sealing wall, built to protect the underground floor of a factory against infiltration of groundwater. 


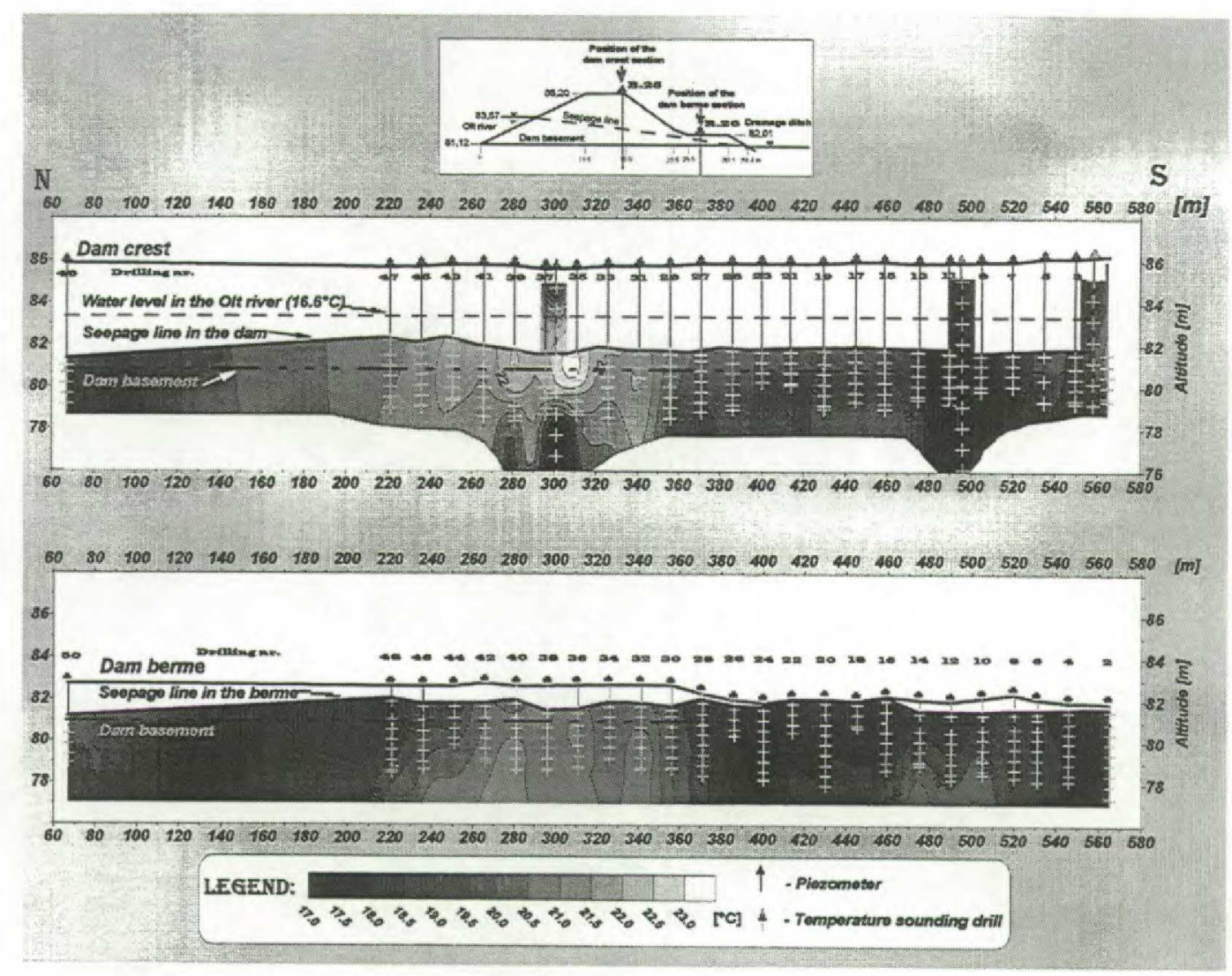

Figure 2: Vertical dam sections with the temperature distribution, measured in piezometers and in special temperature sounding drills

The areal distribution of the inhomogenities in the sealing wall (resistivity maxima) is presented in figure 4 . Wall samples and core drillings, were carried out in the vicinity of the two main resistivity anomalies; they revealed that the material of the sealing wall (cement/bentonite) was being displaced by gravelly sand at these locations. The main contribution of the geophysical investigations in this case led to a specific remediation of the detected inhomogenities in the sealing wall $(300 \mathrm{~m}$ long, $60 \mathrm{~cm}$ wide, meeting quaternary clay at a depth of approx. $16 \mathrm{~m}$ ). The repairs and/or remediation of the sealing wall were therefore much less expensive.

In summary, and in accordance with the examples given above, is intended to emphasize the convergent aspects of the two independent fields of applied geophysics, engineering geophysics and environmental geophysics:

- Both branches, engineering and environmental geophysics, deal with that part of the soil, subsurface and basement, nearest the surface.

- Shallow depths of penetration, high resolution of measurement results and a poor signal/noise relationship due to frequent deployment in disturbed city areas can be seen as characteristic of both branches of applied geophysics.

- The advances in the development of technical equipment and data processing within the context of engineering and environmental geophysics have been considerable in recent years. 


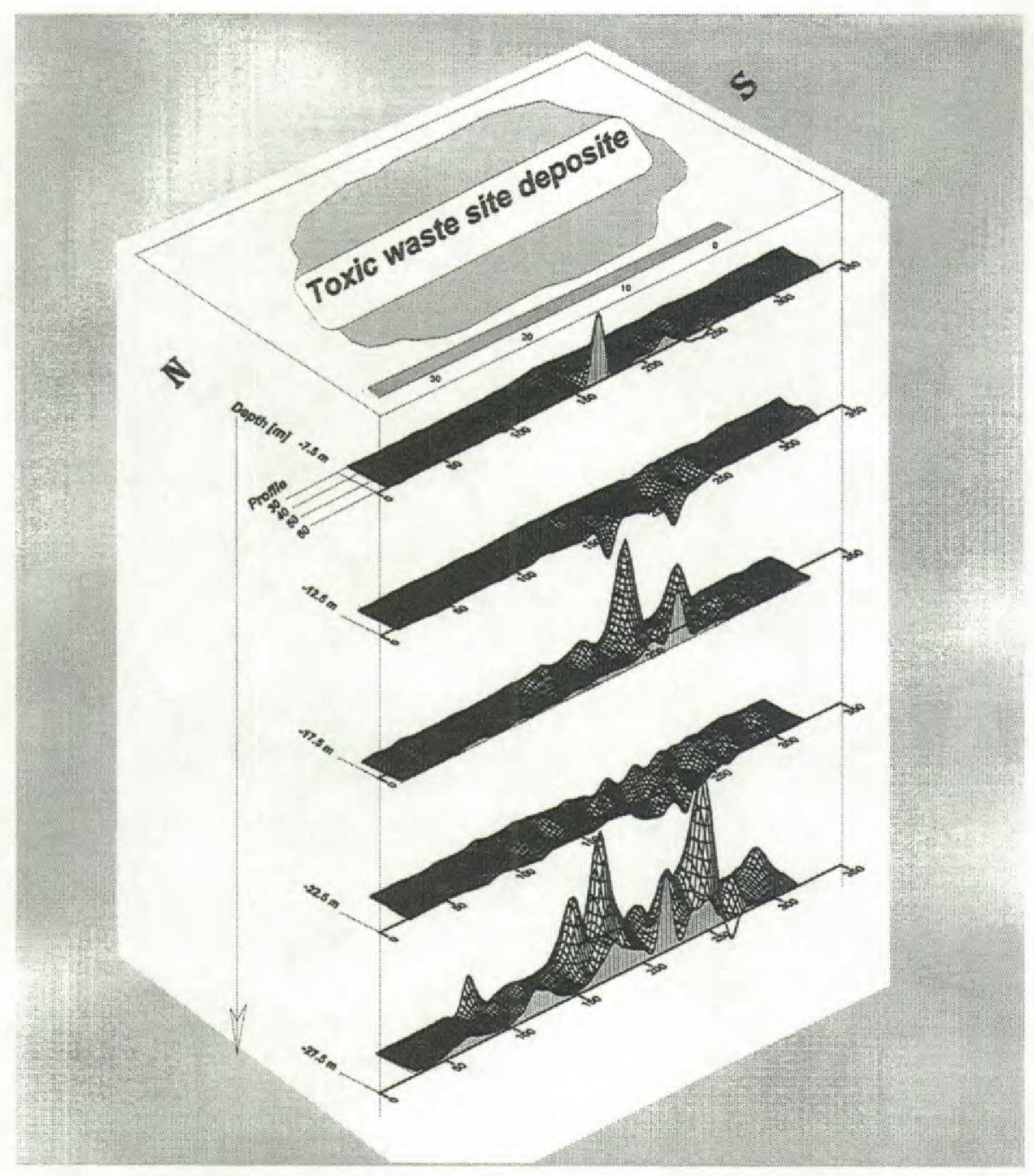

Figure 3: Depth distribution of the induced polarisation anomalies on the west side of the high toxic waste site deposite

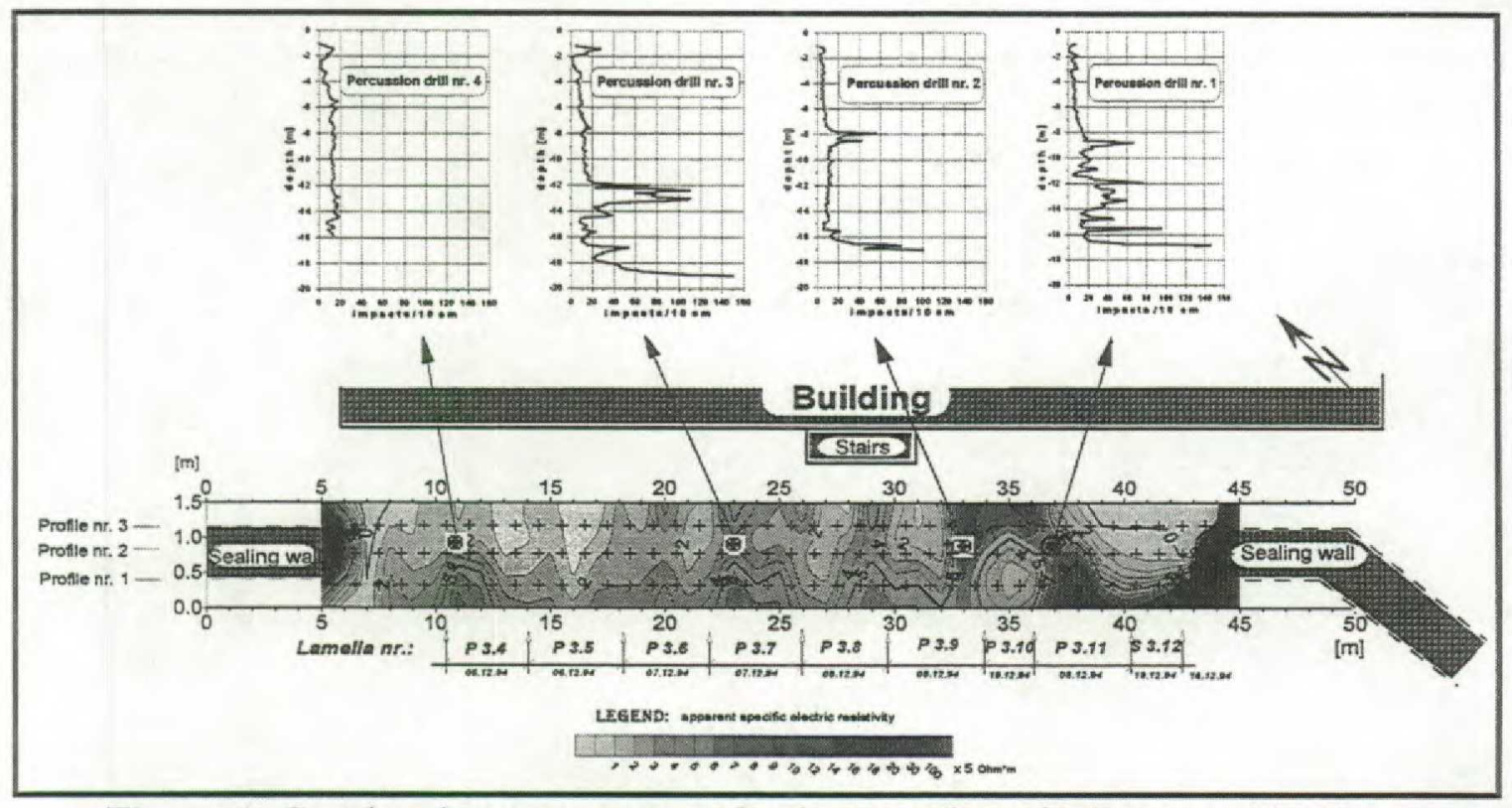

Figure 4: Geoelectric measurements for the detection of inhomogenities in a sealing wall. Pol-dipol electrode array $(\mathrm{AM}=10 \mathrm{~m} ; \mathrm{MN}=1 \mathrm{~m})$ 